Open Journal of Gastroenterology and Hepatology
(ISSN:2637-4986)

\title{
Digestive manifestations of SARS-COV2 infection in Togo
}

BAGNY Aklesso $0^{1,2}$, KOGOE Lidawu Roland-Moïse ${ }^{1^{*}}$, LAWSON-ANANISSOH Laté Mawuli ${ }^{1,2}$, GBOLOU Mawunyo Henoc ${ }^{1}$, REDAH Debehoma Venceslas ${ }^{1}$, KANAKE Yendoukoa Yves ${ }^{1}$

${ }^{1}$ Gastroenterology and hepatology department of Campus teaching hospital, Lome, Togo.

${ }^{2}$ Gastroenterology and hepatology department; University of Lome, Togo.

\section{ABSTRACT}

Objective: to identify the main digestive manifestations related to SARS-CoV-2 in Togo and to determine their impact on the prognosis of the disease. Patients and method: This was a cross-sectional study with retrospective and prospective collection, with descriptive and analytical aims, conducted from May 1, 2020 to April 30, 2021 at the national center for the management of infectious diseases of Lome. Patients of both sexes and of any age, tested positive for SARS-CoV-2 by PCR on nasopharyngeal and oropharyngeal samples and hospitalized at the national center for infectious disease management of Lome were included in this study. Digestive manifestations were divided into gastrointestinal manifestations and hepatobiliary manifestations. The threshold of significance of the tests was retained for a $p$ value less than or equal to 0.05 . Results: out of 876 patients hospitalized during the study period, 215 presented with digestive manifestations, corresponding to a prevalence of $24.54 \%$. the predominance was male, with a male/female sex ratio of 1.74 . the mean age was 46.07+/-16.14 [02 months - 82 years]. gastrointestinal manifestations were found in $11.98 \%$ of cases. abdominal pain was the most frequent digestive symptom (15.35\%). hepatobiliary manifestations were represented by cytolysis syndrome $(44.19 \%)$ and cholestasis syndrome (36.28\%). digestive manifestations were associated with renal failure $(p=0.03)$ and thrombocytosis $(p<0.01)$. The occurrence of death was associated with a decrease in HDL-cholesterol $(p<0.001)$ and the presence of renal failure $(p=0.027)$. The cure rate in our study was $83.72 \%$ with a lethality of $16.27 \%$. Conclusion: the digestive manifestations constitute a not negligible form of revelation of the disease with coronavirus 2019. The best prevention is the vaccination and the respect of the measures of social distanciation.

Keywords: digestive manifestations, COVID-19, SARS-COV 2, prognosis, death, Lome, Togo
*Correspondence to Author:

Dr KOGOE Lidawu Roland-Moïse

Gastroenterology and Hepatology department of Campus teaching hospital of Lome, Togo.

Contact : +228 90023607

How to cite this article:

BAGNY Aklesso, KOGOE Lidawu Roland-Moïse, LAWSON-ANANISSOH Laté Mawuli, GBOLOU Mawunyo Henoc, REDAH Debehoma Venceslas, KANAKE Yendoukoa Yves. Digestive manifestations of SARS-COV2 infection in Togo. Open Journal of Gastroenterology and Hepatology, 2022, 5:59.

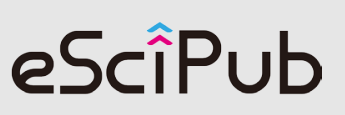

eSciPub LLC, Houston, TX USA. Website: https://escipub.com/ 


\section{Introduction}

In December 2019, a new coronavirus, named SARS-CoV-2, responsible for unexplained severe pneumonia was identified in Wuhan, China [1, 2]. After SARS-CoV-1 in 2002 in China and MERS-CoV (Middle East Respiratory Syndrome) in 2012 in the Arabian Peninsula, responsible for often fatal respiratory distress syndromes, this is the third coronavirus-related global health threat in less than 20 years ${ }^{[3]}$. This virus, enveloped with single-stranded RNA, was quickly responsible for a pandemic of the Coronavirus 2019 or Covid-19 disease declared on March 11, 2020 by the WHO. In its latest report, dated September 28, 2021, WHO states that SARS-CoV-2 has infected more than 231 million people and caused the death of more than 4.7 million people worldwide. In Togo, according to the same report, 25218 people have tested positive for this new coronavirus with 226 deaths. Although the initial manifestations of Covid-19 disease are respiratory, ranging from mild upper respiratory involvement to severe pneumonia with acute respiratory distress syndrome (ARDS), the digestive system appears to be involved in the clinical expression, transmission, and possibly pathogenesis of the disease. Digestive manifestations related to SARS-CoV-2 have been reported, raising the hypothesis of a digestive tropism of the virus ${ }^{[4]}$. In addition, the detection of viral RNA in the stools of infected patients led to the hypothesis of a possible fecaloral transmission of the virus ${ }^{[5,6]}$.

In view of the poor documentation of digestive manifestations related to SARS-CoV-2, manifestations that may be indicative of the infection, it seemed necessary to conduct this study with the objective of identifying the main digestive manifestations related to SARS-CoV-2 in Togo and determining their impact on the prognosis of the disease.

\section{Patients and Method}

This was a cross-sectional study with retrospective and prospective collection, with descriptive and analytical aims, conducted from May 1, 2020 to April 30, 2021 at the national center for the management of infectious diseases of Lome.
Patients of both sexes and of any age, tested positive for SARS-CoV-2 by PCR on nasopharyngeal and oropharyngeal samples and hospitalized at the national center for infectious disease management of Lome were included in this study.

Digestive manifestations were divided into gastrointestinal manifestations, represented by diarrhea, vomiting, abdominal pain and digestive hemorrhage, and hepatobiliary manifestations represented by hepatic cytolysis and hepatic cholestasis. Diarrhea was defined as the emission of more than three episodes of liquid stools per 24 hours. Hepatic cytolysis was defined as an elevation of transaminases (ASAT or ALAT) to more than twice the upper limit of the normal value. Hepatic cholestasis was defined as a concomitant increase in Gamma Glutamyl Transferase (GGT), Alkaline Phosphatase (ALP) activity and bilirubin. Patients with Covid-19 were classified according to WHO into four stages based on severity: Mild, Moderate, Severe and Critical ${ }^{[7]}$. The collected data were entered into a data entry mask designed in EPIDATA 3.1. The statistical audit and analysis had been done with STATA 2013 software; and included a descriptive and an analytical component. Quantitative variables were presented in the form of numbers, means, standard deviations and intervals; qualitative variables in the form of numbers and percentages of tables or figures. Statistical tests used were Fischer's exact test and Chi-square test for categorical variables; and Student's t-test for quantitative variables. The univariate analysis compared patients with digestive manifestations with patients without digestive manifestations and patients who died in hospital with patients who were cured. Variables showing a significant difference between the two groups were inserted into a logistic regression model for multivariate analysis. The threshold of significance of the tests was retained for a $p$ value less than or equal to 0.05 .

\section{Results}

\section{Epidemiological data}

A total of 876 patients were hospitalized at the national center for the management of infectious 
diseases of Lome for Coronavirus 2019 disease \pm 16 years. Seventy-eight (78) patients were fefrom May 1, 2020 to April 30, 2021. Of these 876 male and 137 were male, corresponding to a patients, 215 had presented with digestive mani- male/female sex ratio of 1.74. Demographic and festations, which corresponds to a prevalence of clinical data are detailed in Table I. $24.54 \%$. The average age of the patients was 46

Table I: Demographic and epidemiological characteristics of patients

\begin{tabular}{lccc}
\hline & Digestives manifestations & No digestives manifestations & p-value \\
\hline Mean age (years) & 24,55 & 75,45 & $<0,001$ \\
Gender & & & \\
Male & $137(63,72 \%)$ & $406(61,42 \%)$ & 0,56 \\
Female & $78(36,28 \%)$ & $254(38,43 \%)$ & 0,98 \\
BMI>25 & $37(17,21 \%)$ & $46(6,96 \%)$ & \\
Comorbidities & & & \\
Diabetes & $44(34,11)$ & $85(29,11)$ & $<0,001$ \\
High blood pressure & $75(58,14)$ & $123(42,12)$ & $<0,001$ \\
Asthma & $10(7,75)$ & $21(7,19)$ & 0,31 \\
Chronic renal failure & $2(1,55)$ & $1(0,34)$ & 0,09 \\
HIV & $8(6,20)$ & $14(4,79)$ & 0,19 \\
Symptoms & & & \\
Fever & $84(39,07)$ & $144(21,78)$ & $<0,001$ \\
Dyspnea & $73(33,95)$ & $130(19,67)$ & $<0,001$ \\
Chest pain & $20(9,30)$ & $30(4,54)$ & $<0,001$ \\
Headache & $50(23,25)$ & $116(17,55)$ & 0,06 \\
Severe and critical form & $53(24,65)$ & $78(11,80)$ & $<0,001$ \\
Intensive care & $88(40,93)$ & $111(16,79)$ & $<0,001$ \\
Oxygenation & $60(27,91)$ & $89(13,46)$ & 0,03 \\
Death & $35(17,28)$ & $62(9,38)$ & $<0,001$ \\
\hline & BMI : Body Mass Index & &
\end{tabular}

Table II: Biological data of patients

\begin{tabular}{|c|c|c|c|c|c|}
\hline & \multicolumn{2}{|c|}{ Digestive manifestations } & \multicolumn{2}{|c|}{ No digestive manifestations } & \multirow[t]{2}{*}{$p$-value } \\
\hline & Mean+/-SD & Eff (\%) & Mean+/-SD & n (\%) & \\
\hline Hemoglobin rate & $12,36 \pm 2,7$ & & $12,79 \pm 2,20$ & & 0,04 \\
\hline Anemia & & $91(50,56)$ & & $89(20,75)$ & 0,98 \\
\hline White blood cells & $9009 \pm 6358$ & & $7108 \pm 4757$ & & $<0,001$ \\
\hline Leucopenia & & $19(10,55)$ & & $159(37,06)$ & $<0,001$ \\
\hline Hyperleukocytosis & & $50(27,77)$ & & $128(29,84)$ & $<0,001$ \\
\hline Platelets & $249219 \pm 120285$ & & $238050 \pm 92185$ & & 0,23 \\
\hline Thrombopenia & & $40(22,22)$ & & $135(31,46)$ & $<0,001$ \\
\hline Thrombocytosis & & $23(12,77$ & & $152(35,43)$ & $<0,001$ \\
\hline C-reactive protein & $87,17 \pm 122,69$ & & $31,46 \pm 67,77$ & & $<0,001$ \\
\hline $\mathrm{CRP}>6 \mathrm{mg} / \mathrm{L}$ & & $41(80,39)$ & & $10(10,75)$ & $<0,001$ \\
\hline Creatininemia & $16,77 \pm 20,22$ & & $13,36 \pm 20,53$ & & 0,07 \\
\hline Kidney failure & & $49(28,99)$ & & $120(31,01)$ & $<0,001$ \\
\hline Ions $\mathrm{Na}+$ & $138,5 \pm 7,5$ & & $140 \pm 5,2$ & & 0,08 \\
\hline Hyponatremia & & $15(17,65)$ & & $70(52,63)$ & 0,09 \\
\hline lons $\mathrm{K}_{+}$ & $4,29 \pm 0,8$ & & $4,41 \pm 0,8$ & & 0,26 \\
\hline Hypokaliemia & & $13(15,29)$ & & $71(53,78)$ & 0,21 \\
\hline Hyperkaliemia & & $36(42,35)$ & & $48(36,09)$ & 0,15 \\
\hline Total Cholesterol & $1,79 \pm 1,70$ & & $8,19 \pm 4,54$ & & 0,52 \\
\hline Hypercholesterolemia & & $45(37,19)$ & & $76(25,42)$ & $<0,001$ \\
\hline HDL-cholesterol & $0,42 \pm 0,19$ & & $0,86 \pm 4,91$ & & 0,47 \\
\hline Hypo HDL & & $19(30,65)$ & & $11(6,79)$ & $<0,001$ \\
\hline
\end{tabular}


Table III: Comparison of data for deceased and cured patients

\begin{tabular}{lccc}
\hline & $\begin{array}{c}\text { Dead patients } \\
\mathbf{n}(\%)\end{array}$ & $\begin{array}{c}\text { Healed patients } \\
\mathbf{n}(\%)\end{array}$ & p-value \\
\hline HIV & $3(8,57)$ & $5(2,77)$ & 0,09 \\
Diabetes & $12(34,28)$ & $32(17,77)$ & 0,02 \\
High blood pressure & $17(48,57$ & $58(32,22)$ & 0,06 \\
Chronic kidney failure & $2(5,51)$ & $0(0)$ & $<0,001$ \\
Fever & $19(54,28$ & $65(36,11)$ & 0,04 \\
Dyspnea & $27(77,14)$ & $46(25,55)$ & $<0,001$ \\
Headache & $2(5,71)$ & $48(26,66)$ & $<0,001$ \\
Critical form & $4(11,42)$ & $2(1,11)$ & $<0,001$ \\
Anemia & $20(71,42)$ & $71(46,71)$ & 0,01 \\
Leukocytosis & $18(64,28)$ & $32(21,33)$ & $<0,001$ \\
Thrombopenia & $10(37,03)$ & $30(20,27)$ & 0,05 \\
Acute kidney failure & $23(74,19)$ & $26(18,44)$ & $<0,001$ \\
Hyperkaliemia & $16(61,53)$ & $20(34,48)$ & 0,02 \\
Hypokaliemia & $1(3,84)$ & $12(20,68)$ & 0,04 \\
Hyponatremie & $8(30,76)$ & $7(11,86)$ & 0,03 \\
Hypo-HDL & $13(81,25)$ & $3(13,04)$ & $<0,001$ \\
\hline
\end{tabular}

HDL : High Density Lipoprotein

Table IV : Factors associated with digestive events in multivariate analysis

\begin{tabular}{lcccccc}
\hline & \multicolumn{3}{c}{ Initial model } & \multicolumn{3}{c}{ Final model } \\
\cline { 2 - 7 } & OR & Cl95\% & p-value & ORa & Cla95\% & p-value \\
\hline High blood pressure & 0,97 & {$[0,33-2,83]$} & 0,96 & - & - & - \\
Diabetes & 0,87 & {$[0,30-2,51]$} & 0,79 & - & - & - \\
Fever & 3,04 & {$[1,19-7,74]$} & 0,01 & $\mathbf{1 , 6 9}$ & {$[\mathbf{1 , 1 2 - 2 , 5 4 ]}$} & $\mathbf{0 , 0 1}$ \\
Dyspnea & 0,29 & {$[0,06-1,28]$} & 0,10 & - & - & - \\
BMI $25 \mathrm{~kg} / \mathrm{m} 2$ & 1,29 & {$[0,13-12,65]$} & 0,82 & - & - & - \\
Intensive care & 9,41 & {$[2,02-43,66]$} & 0,004 & $\mathbf{2 , 3 6}$ & {$[\mathbf{1 , 4 9 - 3 , 7 4 ]}$} & $<\mathbf{0 , 0 0 1}$ \\
Hypo HDL-Chol & 1,10 & {$[0,33-3,65]$} & 0,87 & - & - & - \\
Hyper LDL-Chol & 1,46 & {$[0,45-4,79]$} & 0,52 & - & - & - \\
Acute kidney failure & 3,33 & {$[1,15-9,58]$} & 0,02 & - & - & - \\
Anemia & 1,04 & {$[0,46-2,35]$} & 0,90 & - & - & $\mathbf{0}, \mathbf{0 0 7}$ \\
Hyperleucocytosis & 2,63 & {$[0,85-8,11]$} & 0,09 & $\mathbf{2 , 1 0}$ & {$[\mathbf{1 , 2 2 - 3 , 6 2 ]}$} & $\mathbf{0}$
\end{tabular}

OR : Odds ratio ; ORa : adjusted Odds ratio ; $\mathrm{Cl}$ :confidence interval ; Cla :adjusted confidence interval BMI : Body Mass Index ; HDL : Hign Density Lipoprotein ; LDL : Low Density Lipoprotein

Table V: Factors associated with death

\begin{tabular}{lllllll}
\hline & \multicolumn{3}{c}{ Modèle Initial } & \multicolumn{3}{c}{ Modèle Final } \\
\cline { 2 - 7 } & \multicolumn{1}{c}{ OR } & \multicolumn{1}{c}{ IC95\% } & $\mathbf{P}$ & $\mathbf{O R a}$ & ICa95\% & $\mathbf{p}$ \\
\hline High blood pressure & 1,01 & {$[0,02-46,11]$} & 0,57 & - & - & - \\
Diabetes & 24,59 & {$[0,39-1550,29]$} & 0,99 & - & - & - \\
Fever & 6,85 & {$[0,25-186,17]$} & 0,13 & - & - & - \\
Hyponatremia & 2,66 & {$[0,11-60,39]$} & 0,53 & - & - & - \\
Hyperkaliemia & 3,91 & {$[0,21-70,46]$} & 0,35 & - & - & - \\
Hypo HDL-Chol & 110,61 & {$[3,43-3559,96]$} & $\mathbf{0 , 0 0 8}$ & 23,58 & {$[4,62-120,10]$} & $<0,001$ \\
Kidney failure & 59,45 & {$[0,62-5678,56]$} & $\mathbf{0 , 0 1 3}$ & 6,29 & {$[1,23-31,99]$} & $\mathbf{0 , 0 2 7}$ \\
\hline
\end{tabular}

OR : Odds ratio ; ORa : adjusted Odds ratio ; $\mathrm{Cl}$ :confidence interval ; Cla :adjusted confidence interval ; HDL : Hign Density Lipoprotein

\section{Clinical Data}

Abdominal pain (15.35\%), vomiting (14.42\%) and diarrhea (13.95\%) were the most common gastrointestinal manifestations. Apart from the gastrointestinal manifestations, these patients also presented extra-digestive symptoms such as fever, dyspnea and pain. The presence of certain comorbidities such as arterial hypertension OJGH: https://escipub.com/open-journal-of-gastroenterology-and-hepatology/ 
and diabetes mellitus were unequally distributed in the two groups with a statistically significant difference. The severity assessment classified 104 patients (48.37\%) as Mild while 47 patients $(21.86 \%)$ were Severe and $6(2.79 \%)$ as Critical. Eighty-eight (40.93\%) patients with digestive manifestations had required hospitalization in intensive care unit, compared to $111(16.79 \%)$ in patients without digestive manifestations ( $p$ $<0.001$ ).

Statistical analysis noted that the presence of fever $(\mathrm{ORa}=1.69$; Cla95\%: [1.12-2.54] and hospitalization in intensive care unit $(\mathrm{ORa}=2.36$; Cla95\%: [1.49-3.74]; $p<0.001)$ were statistically associated with digestive events during Covid19 infection.

\section{Biological Data}

Liver enzymology found liver cytolysis in 95 patients $(44.19 \%)$ and cholestasis in 78 patients (36.28\%). The blood count data showed a statistical difference between the two groups in some variables such as hemoglobin and white blood cell count. There was also an increase in C-reactive protein in $80.39 \%(p<0.001)$. Decreased plasma HDL cholesterol levels were found in $30.65 \%$ of cases $(p<0.001)$. Hyperleukocytosis was statistically associated with digestive manifestations in multivariate analysis $(\mathrm{ORa}=2.10$; Cla95\%: [1.22-3.62]; $p=0.007$ ).

\section{Evolution}

A high case fatality was found in patients with digestive manifestations $(16.27 \% ; p<0.001)$. Statistical analysis revealed that the risk factors for death in patients with digestive events were lower plasma HDL cholesterol levels as a risk factor for death $(\mathrm{ORa}=23.5 ; 95 \% \mathrm{Cl}$ [4.62-120.10], $\mathrm{p}<0.00)$ and the presence of renal insufficiency (ORa $=6.29 ; 95 \% \mathrm{Cl}$ [1.23-31.99], $\mathrm{p}=0.02$ )

\section{Discussion}

The prevalence of gastrointestinal manifestations during Covid- 19 was $24.54 \%$, similar to the Ramachadran et al data ${ }^{[8]}$.

There was a male predominance with a male/female sex ratio of 1.74 . This male predominance was also found in the series of Papa et al in Italy [9], of Elmunzer et al in North America ${ }^{[10]}$, of Ramachadran in New York ${ }^{[8]}$ and of Nobel et al in
New York [11]. This low prevalence of digestive manifestations during Covid is related with the lower prevalence of Covid-19 in women and that could be explained by the role of innate immunity, steroid hormones and factors related to the $X$ sex chromosomes ${ }^{[12]}$. Indeed, the presence of two $X$ chromosomes in women enhances the action of the immune system. The immune regulatory genes encoded by the $X$ chromosome in women are thought to be related to lower viremia and moderate inflammation compared to men [12].

The mean age of our patients was $46.07 \pm 16.14$ years. Ramachadran et al in New York ${ }^{[8]}$ and Chen et al in China ${ }^{[13]}$ had reported a mean age of 57.6 years and 60 years respectively. These results show that the manifestations are more frequent in young adults.

The gastrointestinal manifestations found in our study were essentially abdominal pain (15.35\%), diarrhea (13.95\%) and vomiting (14.14\%). These data are consistent with those reported in the literature ${ }^{[8,10,13]}$ and confirm the high expression of CEA2 in the gastrointestinal tract and thus the digestive tropism of SARS-Cov-2 [14-16]. The evaluation of the severity of the disease found a moderate form in $26.98 \%$ of cases, a severe form in $21.86 \%$ of cases and a critical form in $2.79 \%$ of cases. Statistical analysis showed that the presence of digestive manifestations during Covid-19 was associated with hospitalization in an intensive care unit (ORa=2.36; Cla95\%: [1.49-3.74]; $p<0.001)$. This result is not consistent with those of Chen et al ${ }^{[13]}$. This discordance could be explained by the lack of standardization of admission criteria in intensive care unit.

Biologically, hepatic cytolysis syndrome was found in $44.19 \%$ of cases, while cholestasis was reported in $36.28 \%$ of cases. These results are consistent with the literature ${ }^{[10,17]}$. These results confirm the theory of hepatic lesions related to the systemic inflammatory reaction of the organism as evidenced by the elevation of biological markers of inflammation including CRP found in $80.39 \%$ of cases. 
The CRP measurement had a mean value of $87.17 \mathrm{mg} / \mathrm{L}$ in patients with digestive manifestations $(p<0.001)$. CRP was elevated to more than $6 \mathrm{mg} / \mathrm{L}$ in $80.39 \%$ of cases $(p<0.001)$. These results are in line with those of Chen et al in China [13], who found a mean CRP of $30.8 \mathrm{mg} / \mathrm{L}$ in patients with digestive manifestations $(p<0.001)$. This statistically significant elevation of CRP could be explained by the fact that the digestive involvement during Coronavirus 2019 disease would be related to the systemic inflammation of the body in response to the presence of SARSCoV-2.

This study found an estimated case fatality of $16.27 \%$. This result is much higher than those reported in the literature ${ }^{[11,13]}$. This high case fatality observed in our study could be explained by the inadequacy of the technical platform, which does not allow for optimal management of patients at the severe or critical stage.

In this study, the presence of digestive manifestations was statistically associated with the occurrence of death $(p<0.001)$ contrary to Chen et al ${ }^{[13]}$ who did not find a significant difference $(p=0.17)$. The cure rate was nevertheless high in our study $(83.72 \%)$ as in the study of Chen et al [13] $(70.75 \%)$. This discrepancy could be explained by the presence of factors associated with death in patients with digestive manifestations. The digestive events taken in isolation would therefore not be associated with the occurrence of death.

Multivariate analysis of factors associated with death in our study population found that low HDL cholesterol $(p<0.001 ; O R=110)$ was associated with death in patients with Gl events. This association between low HDL-Cholesterol and the occurrence of death could be explained by the decreased antioxidant, anti-inflammatory and antiinfectious properties of HDL-Cholesterol [18].

\section{Conclusion}

Digestive manifestations are frequent in Coronavirus 2019 disease. They are generally more frequent in young subjects, with a predominance for the male subject. Gastrointestinal involvement, represented by symptoms such as diarrhea, vomiting, and abdominal pain, is the most frequently encountered presentation, sometimes without associated respiratory symptomatology. Hepatobiliary involvement, which is less common, is related to the tropism of SARS-CoV-2 for hepatocytes and cholangiocytes and is manifested by a cytolysis syndrome and/or a cholestasis syndrome. Digestive symptoms may be associated to varying degrees with classic symptoms of Coronavirus-2019 disease such as fever, cough, dyspnea. Factors associated with the occurrence of digestive manifestations are mainly impaired renal function and thrombocytosis. This digestive involvement is generally responsible for mild or moderate forms of covid-19 with an evolution towards recovery in the vast majority of cases

\section{Aknowlegment : none \\ Conflicts of interest : none \\ References}

[1] Zhu N, Zhang D, Wang W, et al. A novel coronavirus from patients with pneumonia in China, 2019. N Engl J Med.

[2] Wu Y, Ho W, Huang $Y$, et al. SARS-CoV-2 is an appropriate name for the new coronavirus. The Lancet 2020; 395: 949-50.

[3] Wong G, Liu W, Liu Y, et al. MERS, SARS, and Ebola: the role of super-spreaders in infectious disease. Cell Host Microbe 2015; 18: 398-401.

[4] Hanen E, Mohamed G, Riadh B, Héla E. Manifestations digestives de la Covid-19; Prévalence et impact pronostique. In: La Tunisie Médicale2020, pp. 643-50.

[5] Holshue ML, DeBolt C, Lindquist S, et al. First case of 2019 novel coronavirus in the United States. N Engl J Med.

[6] Musa S. Hepatic and gastrointestinal involvement in coronavirus disease 2019 (COVID19): What do we know till now? Arab J Gastroenterol 2020; 21: 3-8.

[7] Characterisation WHOWGotC M of C. A minimal common outcome measure set for COVID-19 clinical research. Lancet Infect Dis 2020; 20: e1927.

[8] Ramachandran P, Onukogu I, Ghanta S, et al. Gastrointestinal symptoms and outcomes in hospitalized coronavirus disease 2019 patients. Dig Dis 2020; 38: 373-9.

[9] Papa A, Covino M, Pizzolante F, et al. Gastrointestinal symptoms and digestive comorbidities in an Italian cohort of patients with COVID-19. Eur Rev Med Pharmacol Sci 2020; 24: 7506-11. 
[10] Elmunzer BJ, Spitzer RL, Foster LD, et al. Digestive manifestations in patients hospitalized with coronavirus disease 2019. Clin Gastroenterol Hepatol 2021; 19: 1355-65.

[11] Nobel YR, Phipps M, Zucker J, et al. Gastrointestinal symptoms and coronavirus disease 2019: a case-control study from the United States. Gastroenterology 2020; 159: 373.

[12] Conti P, Younes A. Coronavirus COV-19/SARSCoV-2 affects women less than men: clinical response to viral infection. J Biol Regul Homeost Agents 2020; 34: 339-43.

[13] Chen R, Yu Y, Li W, et al. Gastrointestinal symptoms associated with unfavorable prognosis of Covid-19 patients: A retrospective study. Front Med 2020; 7: 815.

[14] Bonny V, Maillard A, Mousseaux C, et al. COVID-19: physiopathologie d'une maladie à plusieurs visages. Rev Médecine Interne 2020; 41: $375-89$.
[15] Hashimoto T, Perlot T, Rehman A, et al. ACE2 links amino acid malnutrition to microbial ecology and intestinal inflammation. Nature 2012; 487: 477-81.

[16] Zhang H, Li H-B, Lyu J-R, et al. Specific ACE2 expression in small intestinal enterocytes may cause gastrointestinal symptoms and injury after 2019-nCoV infection. Int J Infect Dis 2020; 96: 19-24.

[17] Chen N, Zhou M, Dong X, et al. Epidemiological and clinical characteristics of 99 cases of 2019 novel coronavirus pneumonia in Wuhan, China: a descriptive study. The lancet 2020; 395: 50713.

[18] Begue F, Tanaka S, Mouktadi Z, et al. Altered high-density lipoprotein composition and functions during severe COVID-19. Sci Rep 2021; 11: 1-16. 